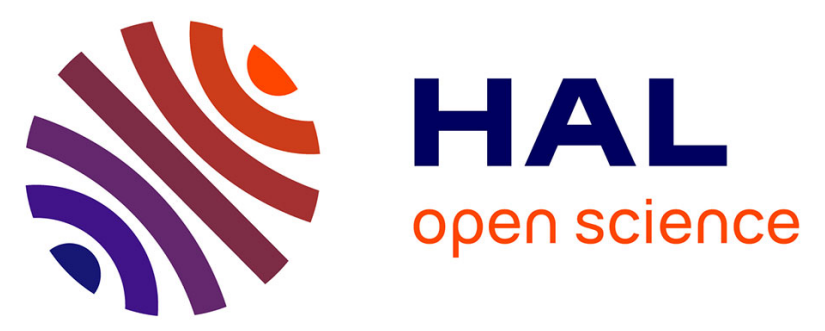

\title{
Nonlinear Adaptive Magnetic Equivalent Circuit of a Radial-Flux Interior Permanent-Magnet Machine using Air-gap Sliding-Line Technic
}

Raouf Benlamine, Youcef Benmessaoud, Frédéric Dubas, Christophe Espanet

\section{- To cite this version:}

Raouf Benlamine, Youcef Benmessaoud, Frédéric Dubas, Christophe Espanet. Nonlinear Adaptive Magnetic Equivalent Circuit of a Radial-Flux Interior Permanent-Magnet Machine using Air-gap Sliding-Line Technic. Vehicle Power and Propulsion Conference, Dec 2017, Belfort, France. hal02131011

\author{
HAL Id: hal-02131011 \\ https://hal.science/hal-02131011
}

Submitted on 16 May 2019

HAL is a multi-disciplinary open access archive for the deposit and dissemination of scientific research documents, whether they are published or not. The documents may come from teaching and research institutions in France or abroad, or from public or private research centers.
L'archive ouverte pluridisciplinaire $\mathbf{H A L}$, est destinée au dépôt et à la diffusion de documents scientifiques de niveau recherche, publiés ou non, émanant des établissements d'enseignement et de recherche français ou étrangers, des laboratoires publics ou privés. 


\section{Nonlinear Adaptive Magnetic Equivalent Circuit of a Radial-Flux Interior Permanent-Magnet Machine using Air-gap Sliding-Line Technic}

\author{
Raouf Benlamine \\ VEDECOM Institute \\ Versailles, France \\ raouf.belamine@vedecom.fr
}

\author{
Youcef Benmessaoud, Frédéric Dubas \\ Département ENERGIE, FEMTO-ST \\ Univ. Bourgogne Franche-Comté \\ Belfort, France \\ youcef.bemessaoud@femto-st.fr \\ FDubas@gmail.com
}

\author{
Christophe Espanet \\ Univ. Bourgogne Franche-Comté \\ Belfort, France \\ christophe.espanet@univ-fcomte.fr
}

\begin{abstract}
This paper describes a two-dimensional (2-D) nonlinear adaptive magnetic equivalent circuit (MEC) of radial-flux interior permanent-magnet (PM) synchronous machines (PMSMs) for automotive application, mainly for electric/hybrid/fuel cell vehicles (EVs/HEVs/FCVs). It includes the automatic mesh of static/moving zones, the saturation effect, and the connection of the zones for the rotor motion which is ensured by a new approach called "Air-gap sliding-line technic". The local/integral quantities at no-load/load (viz., the magnetic flux density, the magnetic flux linkage and the voltage) have been validated with the 2-D finiteelement analysis (FEA) in the case of radial-flux interior PMSM with 18-slots/16-poles having a double-layer concentrated winding (all teeth wound type). The semi-analytical results are in good agreement, considering both amplitude and waveform. The computation time is divided by $3 / 2$ with an error less than $7 \%$.
\end{abstract}

Keywords-Automatic mesh, radial-flux interior PMSMs, magnetic equivalent circuit, saturation effect, sliding-line technic.

\section{INTRODUCTION}

The PMSMs have become the most interesting choice for electric powertrains in automotive applications, mainly $\mathrm{EVs} / \mathrm{HEVs} / \mathrm{FCV}$. This is due to their high torque/power and torque/power density performances [1]. During the last decades, interior PMSMs have been used extensively in EVs and HEVs [2]-[4]. Compared with surface-mounted PMSMs, since the PMs are buried in the rotor iron, interior PMSMs have robust rotor construction and the PMs are shielded from the demagnetizing armature reaction field, as well as the PM eddy-current losses are reduced [5]. Furthermore, due to the difference between $d$ - and $q$-axis inductances, a reluctance torque exists, which enhances the electromagnetic performances. Moreover, interior PMSMs are eminently suitable for automotive applications, which require a wide speed range of constant power operation. This is ensured by higher flux-weakening capability [1]-[2].

During the last decades, different approaches have been developed to study and/or analyze interior PMSMs. Due to the saturation effect and the significant leakage flux caused by magnetic short-circuit inside the rotor, it is difficult to use directly the subdomain technique in Maxwell-Fourier methods to predict the magnetic field distribution although some efforts have been made [6]-[9]. Generally, numerical methods are considered as the best approaches to analyze precisely interior PMSMs. Different studies have been achieved [10]-[12]. However, it is time consuming, which is their main disadvantage. Therefore, a MEC constitutes an excellent compromise to model interior PMSMs with accuracy and less calculation time [13]-[18], which allows to couple with optimization algorithms.

In this paper, the approach proposed in [19] is applied to study a radial-flux interior PMSM for automotive application. The developed semi-analytical model includes the automatic mesh of static/moving zones, the saturation effect, and zones connection in accordance with rotor motion based on a new approach called "Air-gap sliding-line technic", which was applied in [20]-[23] on different electrical machine configurations (i.e., axial-flux interior PM machine, coaxial magnetic gear equipped with surface-mounted PMs, and wound-rotor synchronous machine). This novel technique of connection between static/moving zones is applied for the first time on a radial-flux interior PMSM. Nevertheless, it should be noted that there are other techniques permitting to connect static/moving zones in electrical machines, which have been overviewed in [19]. In section II, the 2-D nonlinear adaptive MEC is described. To account for the saturation effect, an iterative process is considered. The nonlinear $B(H)$ curve of the iron is then introduced by using the Marrocco's interpolation function. In section III, the radial-flux interior PMSM with 18-slots/16-poles having a double-layer concentrated winding (all teeth wound type) has been studied for no-load/load operating points. In order to evaluate the reliability of the proposed method, the magnetic flux density, the magnetic flux linkage, and the voltage are compared to 2D FEA calculation [24]. Finally, the computation time and precision are analyzed.

\section{2-D NONLINEAR ADAPTIVE MEC}

\section{A. Problem Description}

The generalized nonlinear adaptive MEC has been applied to a radial-flux interior PMSM with 18-slots/16-poles (i.e., fractional-slot number) [see Fig. 1]. This electrical machine is used for automotive application (i.e., $16 \mathrm{~kW} @ 1,000 \mathrm{rpm}$ ), mainly for EVs/HEVs/FCVs.

The topology of the machine is represented in Fig. 1(a). The stator has a double-layer concentrated winding distribution (viz., the non-overlapping winding with all teeth wound), supplied by sinusoidal current waveform with a maximum amplitude of $I_{\text {s max }}$. The 3-phase windings are star-connected. The winding schematic, having $N_{s t p}$ serie turns per phase, is 


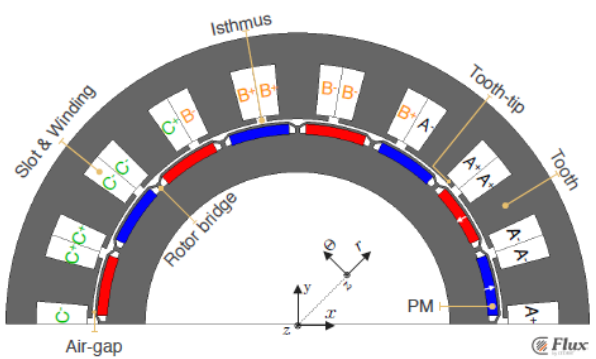

(a)

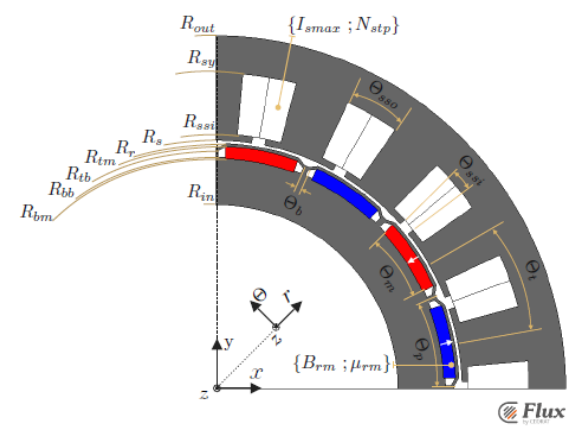

(b)

Fig. 1. Radial-flux interior PMSM (with 18-slots/16-poles): (a) Topology, and (b) Geometrical \& physical parameters.

TABLE I GEOMETRICAL AND PHYSICAL PARAMATERS OF THE RADIAL-FLUX INTERIOR PMSM.

\begin{tabular}{|l|c|}
\hline \multicolumn{1}{|c|}{ Parameters [Units] } & Values \\
\hline$Q_{s} / 2 p[-]$ & $18 / 16$ \\
\hline$L_{z}[\mathrm{~mm}]$ & 70 \\
\hline$\left\{R_{\text {out }} ; R_{s y} ; R_{s s i} ; R_{s}\right\}[\mathrm{mm}]$ & $\{115 ; 103 ; 83 ; 81\}$ \\
\hline$\left\{R_{r} ; R_{t m} ; R_{t b} ; R_{b b} ; R_{b m} ; R_{i n}\right\}[\mathrm{mm}]$ & $\{80 ; 79 ; 72.5 ; 74.5 ; 75 ; 60\}$ \\
\hline$\left\{\Theta_{s s o} / \Theta_{t} ; \Theta_{s s i} / \Theta_{s s o}\right\}[\%]$ & $\{50 ; 30\}$ \\
\hline$\left\{\Theta_{m} / \Theta_{p} ; \Theta_{b} / \Theta_{p}\right\}[\%]$ & $\{78 ; 5.95\}$ \\
\hline$\left\{\mu_{r m} ; \mu_{r i}\right\}[-]$ & $\{1.05 ; 6,000\}$ \\
\hline$B_{r m}[T]$ & 1.15 \\
\hline$I_{s m a x}[A]$ & 282.8 \\
\hline$N_{s t p}[-]$ & 39 \\
\hline
\end{tabular}

depicted in Fig. 1(a). Due to the periodicity of the winding, the machine can be studied according 9-slots/8-poles. The PMs, inserted in the rotor core and radially magnetized, are isotropic and have a linear demagnetization characteristic with a maximum operating temperature $T_{m f}$ equal to $100^{\circ} \mathrm{C}$. The rotor bridge must be as thin as possible to avoid flux leakage. Its thickness should be obtained by optimal design to ensure best electromagnetic performances and mechanical robustness. The geometrical and physical parameters of the studied radial-flux interior PMSM are represented in Fig. 1(b) and given in TABLE I.

\section{B. Automatic Mesh}

The electrical machine is decomposed into two zones, i.e., a static zone and a rotary zone. Each zone can be modeled independently and the interconnecting between the two zones is accomplished by an "Air-gap sliding-line technic" [19]. Consequently, the stator or/and rotor topology can be replaced by another type of construction. The stator (rotor) is divided into 3 (4) zones in the $r$-axis and 5 (5) zones in the $\Theta$-axis. The mesh elements having the same magnetic permeability
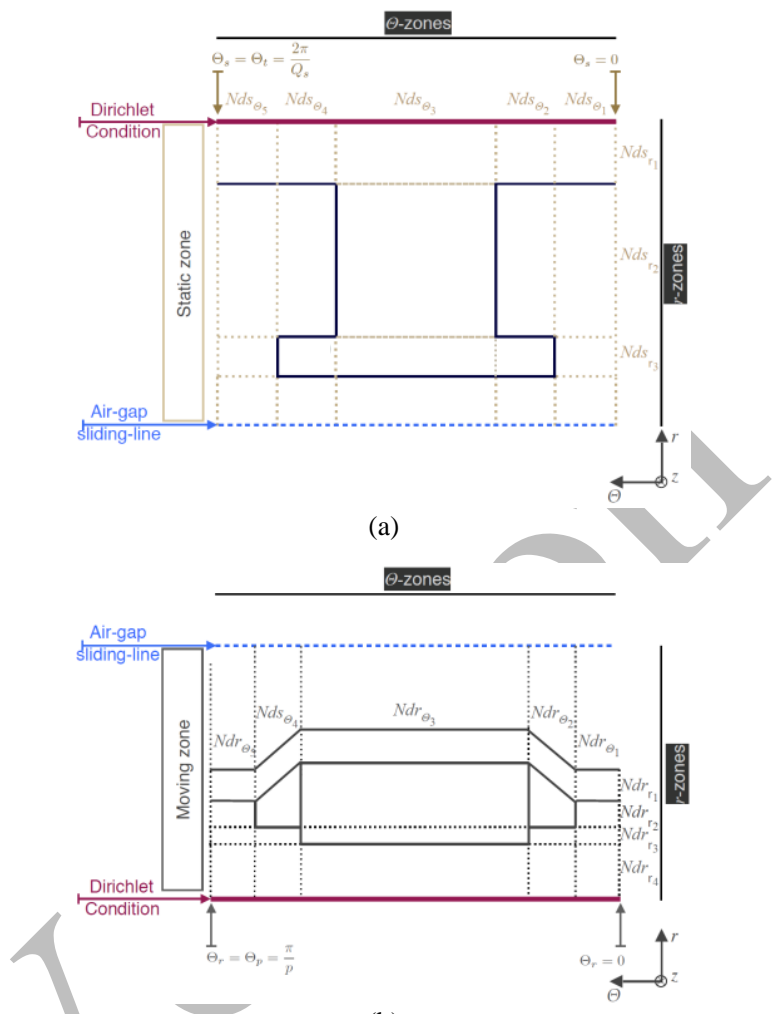

(b)

Fig. 2. Mesh elements of the radial-flux interior PMSM in $(r, \Theta, z)$ coordinate system: (a) Static zone under a tooth-pitch, and (b) Moving zone under a pole-pitch.

(i.e., the same material), resulting from the intersection of zones in the $r$ - and $\Theta$-axis, can be discretized into one or several bidirectional (BD) blocks from $N d s_{r} \quad\left(N d r_{r}\right)$ and $N d s_{\Theta}\left(\boldsymbol{N} \boldsymbol{d} r_{\Theta}\right)$. The air-gap is divided into a single zone according to r-axis discretized into $\mathrm{Ndag}_{r}$, which must be an odd discretization number to display the sliding-line in the airgap. The mesh elements of the static (moving) zone under a tooth-pitch (pole-pitch) are described in Fig. 2. The static (moving) zone under a tooth-pitch (pole-pitch) have to be duplicated 9 (8) times to obtain the Fig. 1(a).

The BD blocks depending on the discretization chosen by the designer, connected between them by the loop fluxes $\psi$ and giving the possibility to magnetic flux to flow in both axes, are described by a middle-point related to (except in the stator and rotor edges due to the Dirichlet conditions):

- 4 magnetomotive forces (MMFs) of branches (i.e., two $r$-MMFs and two $\Theta$-MMFs);

- $\quad$ and 4 magnetic reluctances (i.e., two $r$-reluctances and two $\Theta$-reluctances) crossed by branch fluxes $\phi$.

\section{Magnetic Reluctances}

The magnetic reluctances of BD blocks in the mesh elements are defined by

$\Re *_{r / \Theta}=\frac{\beta *_{r / \Theta}}{\mu_{0} \cdot \mu_{r}\left(B *_{r / \Theta}\right)}$ with $*=\{s, s l, r\}$

where $\{s, s l, r\}$ are respectively the index of the $\{$ static zone, sliding-line, moving zone $\} ; \mu_{0}$ is the vacuum permeability, 
$\beta *_{r / \Theta}$ is the length to surface ratio in the $r$ - or $\Theta$-axis (only the $\Theta$-axis for the sliding-line) which depends on the shape and the discretization of mesh elements as well as the position for the sliding-line contrary to those of reluctances in the static and moving zones; $B *_{r / \Theta}$ is the $\mathrm{r}$ - or $\Theta$-component of magnetic flux density; and $\mu_{r}(\bullet)$ is the relative permeability defined by

$\mu_{r}(\bullet)=\mid \begin{array}{ll}B(H) \text { curve } \quad \text { in the iron parts } \\ 1 \quad \text { in the vacuum, winding or sliding-line } \\ \mu_{r m} \quad \text { in the PMs }\end{array}$

in which $\mu_{r m}$ is the relative magnetic permeability of the PMs. The saturation effect is taken into account by interpolation of the nonlinear $B(H)$ curve with a mathematical formulation , e.g., the Marrocco's function [25]. The relative magnetic permeability can be expressed by

$$
\mu_{r}(\bullet)=\frac{1}{k_{2}+\left[b^{2 \cdot k_{1}}+k_{3} \cdot\left(2 \cdot k_{1}+1\right)\right] \cdot \frac{\left(k_{4}-k_{1}\right) \cdot b^{2 \cdot k_{1}}}{\left(b^{2 \cdot k_{1}}+k_{3}\right)^{2}}}
$$

where $b$ is the magnetic flux density divided by $1 T, k_{1} \sim k_{4}$ are the interpolation coefficients obtained by minimizing the square-error between the nonlinear $B(H)$ curve given by the manufacturer and the values obtained by the Marrocco's function. For the studied machine, the M330-35A steel has been considered. The interpolation coefficients for this ferromagnetic steel are given in TABLE II, whose the interpolation error is less than $7 \%$.

\section{Electromagnetic Sources-MMFs}

The branch MMFs in the BD blocks can be expressed by

$$
M M F=\mid \begin{array}{r}
\begin{array}{r}
\text { in the air (except the slot) and iron } \\
(\text { except the teeth) }
\end{array} \\
f\left(B_{r m} / \mu_{0}, \mu_{r m}, l B\right) \quad \text { in the PMs } \\
f\left(N_{s t p},[C w], i_{s_{g}}\right) \text { in the slot/winding/teeth }
\end{array}
$$

where $B_{r m}$ is the remanent flux density of the PMs at $T_{m f}$, $l B$ is the branch length in the BD blocks crossed by $\phi,[C w]$ is the winding connection matrix between the $m$-phases and the stator slots that represents the stator windings distribution, and $i_{s_{g}}$ is the armature currents of $m$-phases in Fourier series [26].

\section{E. $\quad$ Matrix Formulation and Solving}

The different steps of the nonlinear system solving are presented in the flowchart in Fig. 3. In this figure, $\mu_{r i}$ represents the initial relative permeability in the magnetic circuit and $N_{\text {sat }}$ is the total iterations number for taking into account the saturation effect. By using the Maxwell's equations as well as the magnetic material equations, the 2-D nonlinear adaptive MEC (where the loop fluxes $\psi$ are the unknowns) can be
TABLE II INTERPOLATION COEFFICIENTS OF MARROCCO'S FUNCTION FOR THE M330-35A STEEL.

\begin{tabular}{|c|c|}
\hline Coefficients [Units] & Values \\
\hline$\left\{k_{1} ; k_{2} ; k_{3} ; k_{4}\right\}[-]$ & $\left\{6.38 ; 1.62 \times 10^{-4} ; 6.27 \times 10^{4} ; 6.69\right\}$ \\
\hline
\end{tabular}

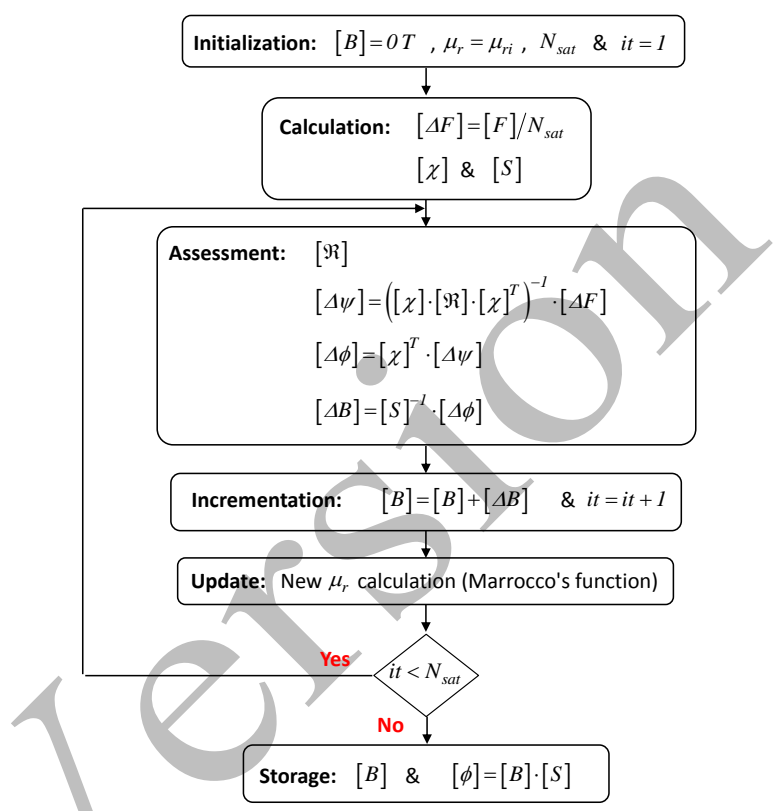

Fig. 3. Flowchart of the iterative solving of the nonlinear system $\left(\forall \Theta_{r s}\right.$ where $\Theta_{r s}$ is the mechanical angular position between the rotor and the stator) [19].

expressed by the following Cramer's system, $\forall \Theta_{r s}$

$[F]-[\chi] \cdot[\Re] \cdot[\chi]^{T} \cdot[\psi]=O$ with $[F]=[\chi] \cdot[M M F]$

where $[\mathfrak{R}]$ is the diagonal matrix of reluctances (of dimension $N \times N$ with $N$ the total number of branch fluxes, branch MMFs or reluctances), $[\psi]$ is the loop fluxes vector (of dimension $N_{\psi} \times 1$ with $N_{\psi}$ the total number of loop fluxes), $[\chi]$ is the topological (or incidence) matrix (of dimension $N_{\psi} \times N$ ), $[F]$ is the loop MMFs vector (of dimension $\left.N_{\psi} \times 1\right),[M M F]$ is the branch MMFs vector (of dimension $N \times 1$ ). These matrixes and vectors are dependent upon the discretization of the various zones. Their dimensions are invariable with $\Theta_{r s}[19]$.

Analytically, (5) can be solved iteratively with a constant relative magnetic permeability according to the nonlinear $B(H)$ curve at each iteration by using the fixed point iteration method. Knowing $[\psi]$, the magnetic flux densities vector $[B]$ (of dimension $N \times 1$ ) are defined by

$$
\begin{aligned}
& {[\phi]=[\chi]^{T} \cdot[\psi]} \\
& {[B]=[S]^{-1} \cdot[\phi]}
\end{aligned}
$$

where $[S]$ is the vector of the corresponding reluctance surface (of dimension $N \times 1$ ) in the various BD blocks, and $[\phi]$ is the branch fluxes vector (of dimension $N \times 1$ ). 
III. COMPARISON OF THE NONLINEAR ADAPTIVE MEC AND FINITE-ELEMENT CALCULATIONS

\section{A. Introduction}

For the comparison, the radial-flux interior PMSM has been modeled using Cedrat's Flux2D software package (i.e., an advanced finite-element method based numeric field analysis program) [24]. The 2-D FEA is done with the same assumptions as in the semi-analytical model. The 2-D nonlinear adaptive MEC has been implemented in Matlab ${ }^{\circledR}$ by using the sparse matrix/vectors. The stator and rotor discretizations have been considered as follows

$$
\begin{aligned}
& N d s_{r}=\left[\begin{array}{lll}
1 & 1 & 1
\end{array}\right] \text { and } N d s_{\Theta}=\left[\begin{array}{lllll}
1 & 1 & 5 & 1 & 1
\end{array}\right] \\
& N d r_{r}=\left[\begin{array}{llll}
1 & 1 & 1 & 1
\end{array}\right] \text { and } N d r_{\Theta}=\left[\begin{array}{lllll}
1 & 1 & 5 & 1 & 1
\end{array}\right]
\end{aligned}
$$

The air-gap zone is discretized into $N d r_{a g}=3$. Consequently, (5) is composed of $N_{\psi}=684$ loop fluxes and $N=2,890$ branch fluxes, which is much smaller than the 2-D FEA mesh having 50,551 surfaces elements of second order (viz., the triangles number of system). The mesh of the machine is presented in Fig. 4(a). The discretization $N_{p t s}$ corresponding to $\Theta_{r s}$ for the rotor motion in the semi-analytical model is equal to 45 . The total number of iterations for magnetic convergence $N_{\text {sat }}$ was imposed on 30 with an initial relative permeability $\mu_{r i}=6,000$. The computation time is divided by $3 / 2$ with respect to numeric.

\section{B. Results Discussion}

1) Magnetic Flux Density: The magnetic flux density is calculated in the various parts of the machine. In this paper, the
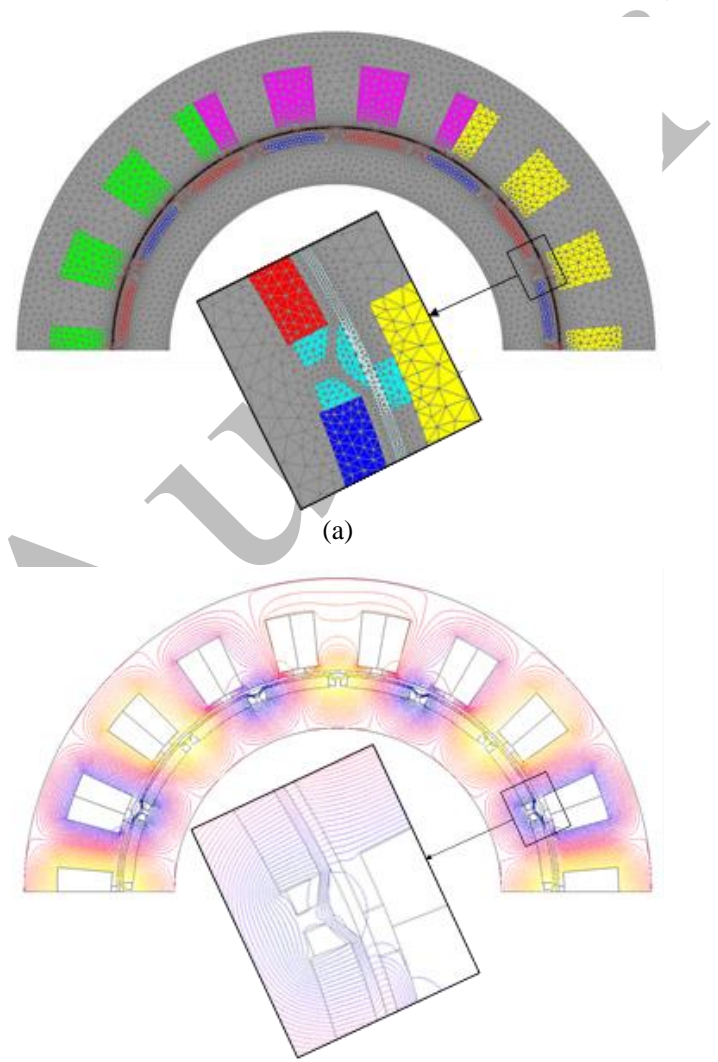

(b)

Fig. 4. Radial-flux interior PMSM with 18-slots/16-poles: (a) Mesh, and (b) Equipotential lines of magnetic potential vector at no-load. results obtained by the 2-D nonlinear MEC are presented and compared to 2-D FEA in three parts of the machine [see Fig. 2]:

- Zone 3 (i.e., isthmus/tooth-tips/teeth) in the static zone;

- Zone 1 (i.e., bridge/iron inter-pole) in the moving zone.

- Static and moving air-gap.

The $r$ - and $\Theta$-component of $\vec{B}$ at load ( $I_{s \max } @ 1,000 \mathrm{rpm}$ ) are illustrated in Fig. 5-8. The components of $\vec{B}$ in the isthmus/tooth-tips/teeth [see Fig. 5] as well as in the bridge/iron inter-pole [see Fig. 6] are very saturated. The results are in good agreement with 2-D FEA, which confirms that the nonlinear solving method is accurate. The components of $\vec{B}$ in the static and moving air-gap [see Fig. 7-8] are in good agreement with the 2D-FEA, which confirms the reliability of the proposed method concerning the zones connection for the rotor motion. Fig. 4(b) shows the equipotential lines of magnetic potential vector for the initial rotor position (i.e., $\Theta_{r s}=O$ ) at no-load. Due to the fractional-slot number, the magnetic flux path is difficult to predict, over the different rotor positions. Therefore, the automatic mesh developed for the MEC appears as a good general solution with an error less than $7 \%$.

2) Magnetic Flux linkage and Voltage: The magnetic flux linkage and the voltage for the three phases are presented in Fig. 9-10 for the no-load (0 A @ 1,000 rpm) and load operating. The rotor has been rotated over one electrical period. The no-load voltage corresponds to the back electromotive force (EMF) of the machine. The results obtained by the 2-D nonlinear MEC are very accurate compared to 2-D FEA. However, errors appears in the voltage calculation due to numerical derivative. The accuracy can be improved by increasing the number of steps over one electrical period (45 steps have been used), at the detriment of the calculation time.

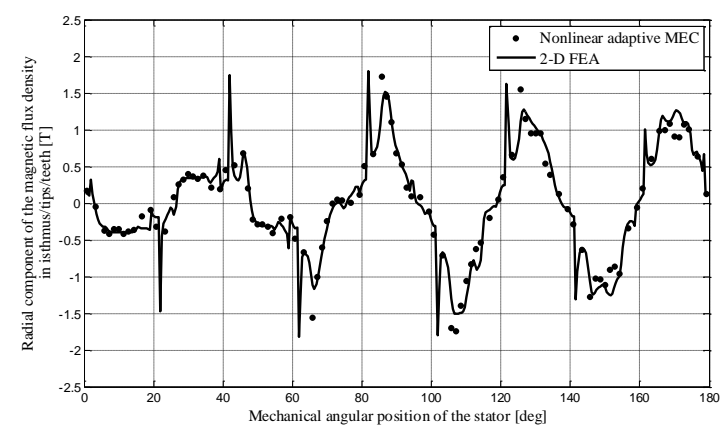

(a)

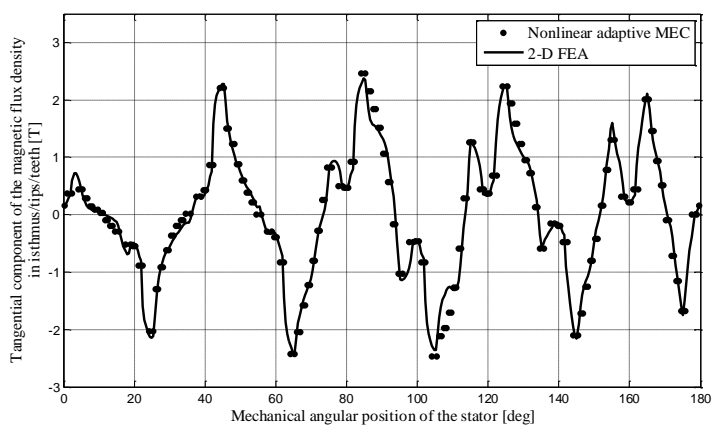

(b)

Fig. 5. Waveforms of the (a) $r$ - and (b) $\Theta$-component of $\vec{B}$ in the isthmus/tooth-tips/teeth at load. 


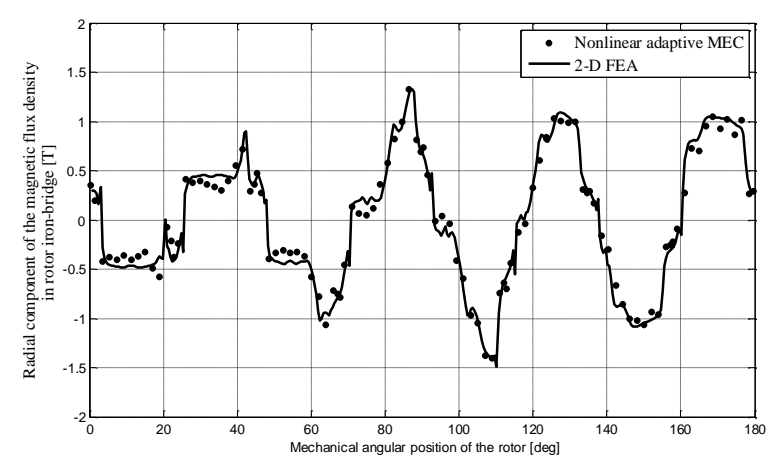

(a)

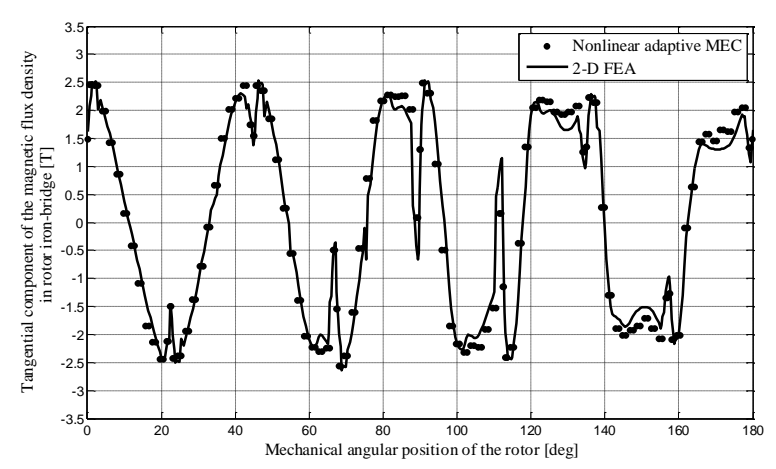

(b)

Fig. 6. Waveforms of the (a) $r$-and (b) $\Theta$-component of $\vec{B}$ in the bridge/iron inter-pole at load.

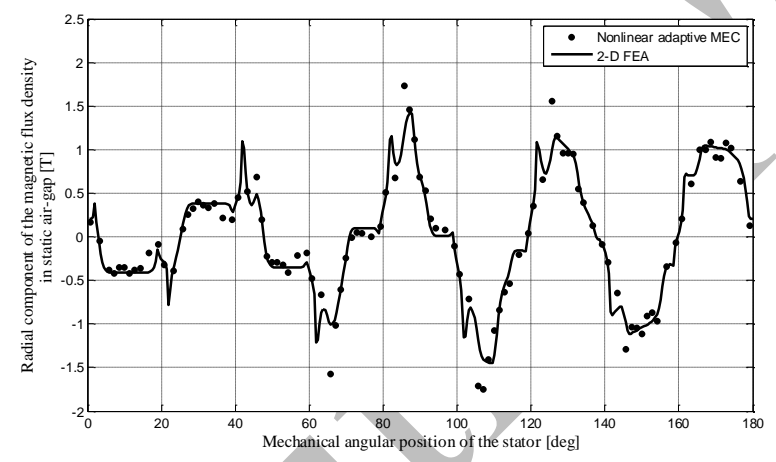

(a)

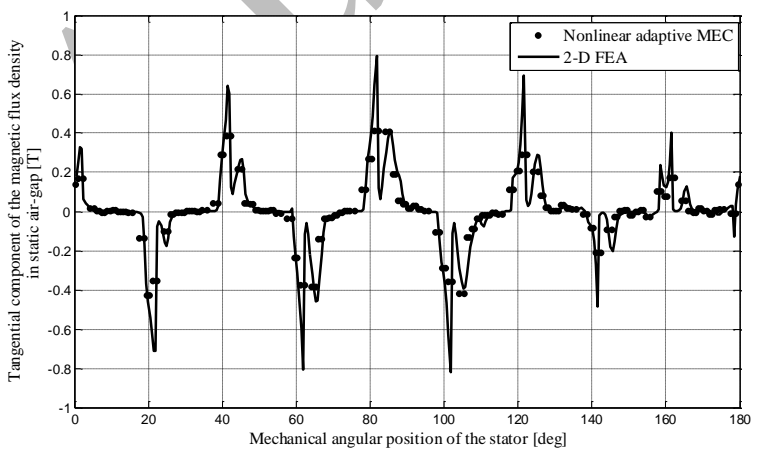

(b)

Fig. 7. Waveforms of the (a) $r$ - and (b) $\Theta$-component of $\vec{B}$ in the static airgap at load.

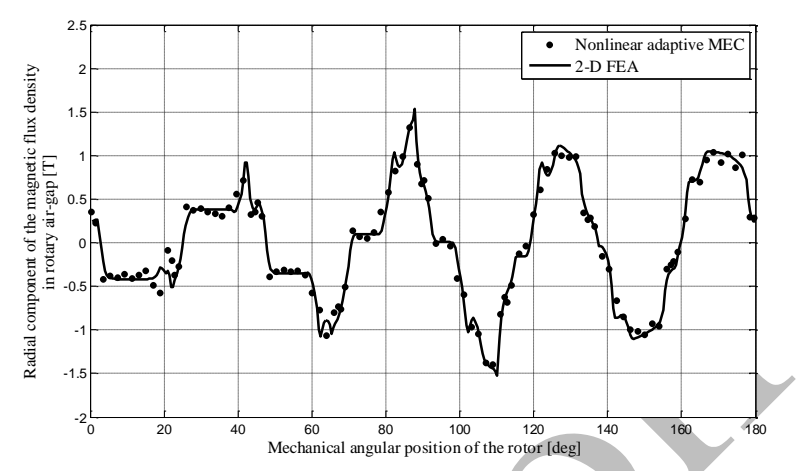

(a)

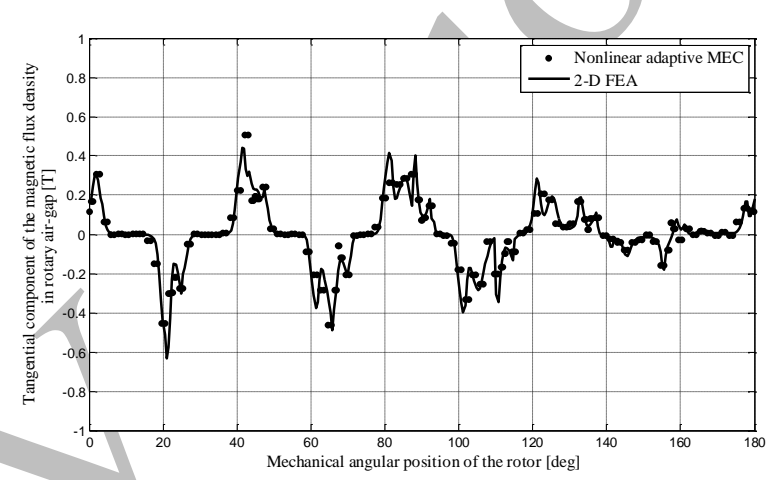

(b)

Fig. 8. Waveforms of the (a) $r$ - and (b) $\Theta$-component of $\vec{B}$ in the moving airgap at load.

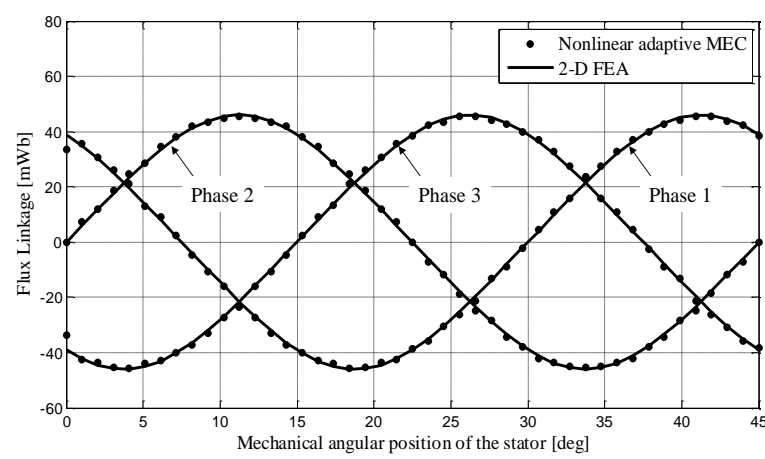

(a)

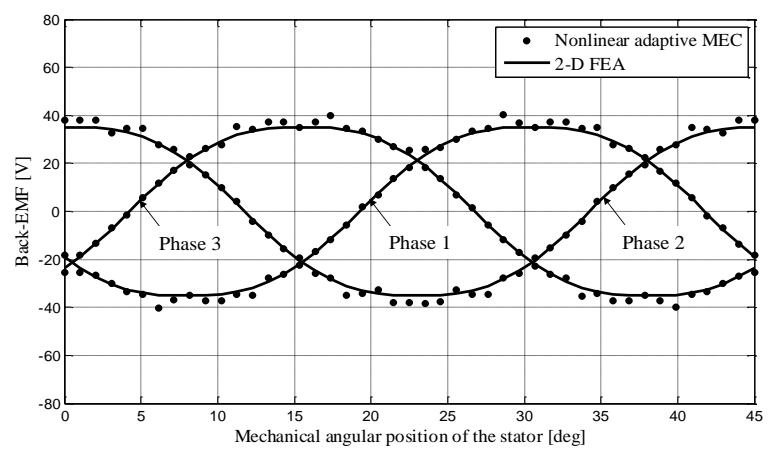

(b)

Fig. 9. Waveforms of the (a) magnetic flux linkage and (b) back EMF at no-load. 


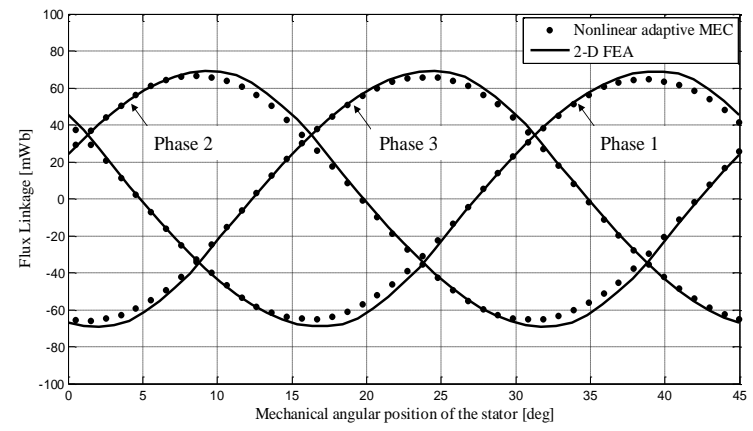

(a)

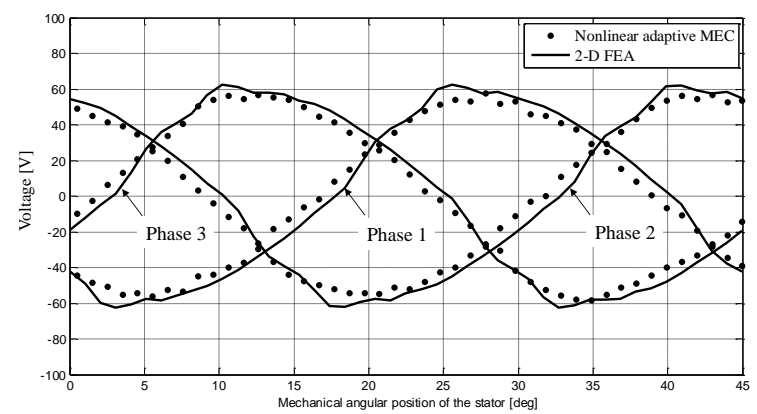

(b)

Fig. 10. Waveforms of the (a) magnetic flux linkage and (b) voltage at load.

\section{CONCLUSION}

In this paper, a 2-D nonlinear adaptive MEC of a radial-flux interior PMSM has been developed. It includes the automatic mesh of static/moving zones, the saturation effect and the rotor motion. The local quantities such as the magnetic flux density in the different parts of the machine can be calculated with high accuracy, including in the saturated zones. The integral quantities (viz., the magnetic flux linkage and the voltage) at no-load/load can also be calculated precisely. The obtained results have been validated with the 2-D FEA considering radial-flux interior PMSM with 18-slots/16-poles having a double-layer concentrated winding (all teeth wound type). The computation time is divided by $3 / 2$ with respect to numeric. The error is less than $7 \%$.

\section{ACKNOWLEDGMENT}

This work was supported by the RENAULT-SAS, Guyancourt, France. This scientific study is related to the project "Conception Optimale des Chaînes de Traction ÉLectrique" (COCTEL) financed by the "Agence de l'Environnement et de la Maîtrise de l'Énergie” (ADEME).

\section{REFERENCES}

[1] Z.Q. Zhu, and D. Howe, "Electrical machines and drives for electric, hybrid, and fuel cell vehicles," in Proc. IEEE, vol. 95, no. 4, pp. 746765, Apr. 2007

[2] M.A. Rahman, and M.A. Masrur, "Advances on IPM technology for hybrid electric vehicles," in Proc. VPPC, Lille, France, 07-12 Sep. 07-12, 2009.

[3] A.M. EL-Refaie, "Motors/Generators for traction/propulsion applications: A review," in Proc. EMDC, Niagara Falls Ontanio, May 14-17, 2011.

[4] R. Benlamine, S-A. Randi, D. Lhotellier, F. Dubas, and C. Espanet, "Design of an axial-flux interior permanent-magnet synchronous motor for automotive application: Performance comparison with electric motors used in EVs and HEVs," in Proc. VPPC, Coimbra, Portugal, Oct. 27-30, 2014.

[5] R. Benlamine, F. Dubas, S-A. Randi, D. Lhotellier, and C. Espanet, "3D numerical hybrid method for PM eddy-current losses calculation:
Application to axial-flux PMSMs," IEEE Trans. on Magn., vol. 51, no. 7 , Jul. 205.

[6] K. Boughrara, R. Ibtiouen, and T. Lubin, "Analytical prediction of magnetic field in parallel double excitation and spoke-type permanentmagnet machines accounting for tooth-tips and shape of polar pieces," IEEE Trans. on Magn., vol. 48, no. 7, pp. 2121-2137, Jul. 2012.

[7] P. Lang, F. Chai, Y. Li, adn Y. Pei, "Analytical prediction of magnetic field distribution in spoke-type permanent-magnet synchronous machines accounting for bridge saturation and magnet shape," IEEE Trans. on Ind. Elec., vol. 64, no. 5, pp. 3479-3488, May 2017.

[8] L. Roubache, K. Boughrara, F. Dubas, and R. Ibtiouen, "Semi-analytical modeling of spoke-type permanent-magnet machines considering the iron core relative permeability: Subdomain technique and Taylor polynomial,' Progress In Electromagnetics Research B, vol.70, pp.113-130, Oct. 2016.

[9] L. Roubache, K. Boughrara, F. Dubas and R. Ibtiouen, "Semi-analytical modeling of spoke-type permanent-magnet machines considering nonlinear magnetic saturation: Subdomain technique and Taylor polynomial," Mathematics and Computers in Simulation., 2017, under review

[10] M-S. Kim, W. Jeon, Y-S. Jeong, and S-Y, Jung, "Numerical identification of synthetic flux linkages considering cross-magnetization for interior PM synchronous motor and its effective availability on design and control," in Proc. IECON, Orlando, Florida, Nov. 10-13, 2008.

[11] A. Wang, Y. Jia, and W.L. Soong, "Comparison of five topologies for an interior permanent-magnet machine for a hybrid electric vehicle," IEEE Trans. on Magn., vol. 47, no. 10, pp. 3606-3609, Oct. 2011.

[12] F. Charih, F. Dubas, C. Espanet, and D. Chamagne, "Performances comparison of PM machines with different rotor topologies and similar slot and pole numbers," in Proc. SPEEDAM, Sorrento, Italy, Jun. 20-22, 2012.

[13] K. Nakamura, K. Saito, and O. Ichinokura, "Dynamic analysis of interior permanent magnet motor based on a magnetic circuit model," IEEE Trans. on Magn., vol. 39, no. 5, pp. 3250-3252, Sep. 2003.

[14] S.H. Han, T.M. Jahns, and W.L. Soong, "A magnetic circuit model for an IPM synchronous machine incorporating moving airgap and crosscoupled saturation effects," in Proc. IEMDC, Antalya, Turkey, May 03$05,2007$.

[15] L. Zhu, S.Z. Jiang, Z.Q. Zhu, and C.C Chan, "Analytical modeling of open-circuit air-gap field distributions in multisegment and multilayer interior permanent-magnet machines," IEEE Trans. on Magn., vol. 45, no. 8, pp. 3121-3130, Aug. 2009.

[16] J.K. Tangudu, T.M. Jahns, A. EL-Refaie, and Z.Q. Zhu, "Lumped parameter magnetic circuit model for fractional-slot concentratedwinding interior permanent magnet machines," in Proc. ECCE, San José, California, Sep. 20-24, 2009.

[17] A.R. Tariq, C.E. Nino-Baron, and E.G. Strangas, "Iron and magnet losses and torque calculation of interior permanent magnet synchronous machines using magnetic equivalent circuit," IEEE Trans. on Magn., vol. 46, no. 12 , pp. 4073-4080, Dec. 2010.

[18] J.K. Tangudu, and T.M. Jahns, "Scalability characteristics of magnetic circuit model for fractional-slot concentrated winding IPM machines," in Proc. ECCE, Raleigh, North Carolina, Sep. 15-20, 2012.

[19] F. Dubas, R. Benlamine, S-A. Randi, D. Lhotellier, and C. Espanet, "2 D or quasi 3-D nonlinear adaptive magnetic equivalent circuit, Part I: Generalized modeling with air-gap sliding-line technic," Applied Energy, 2017, under review.

[20] R. Benlamine, F. Dubas, S-A. Randi, D. Lhotellier, and C. Espanet, "2$\mathrm{D}$ or quasi 3-D nonlinear adaptive magnetic equivalent circuit, Part II: Application to axial-flux interior permanent-magnet synchronous machines," Applied Energy, 2017, under review.

[21] R. Benlamine, F. Dubas, F., S-A. Randi, D. Lhotellier, and C. Espanet, "Modeling of an axial-flux interior PMs machine for an automotive application using magnetic equivalent circuit," in Proc. ICEMS, Pattaya, Thailand, Oct. 25-28, 2015.

[22] R. Benlamine, T. Hamiti, F. Vangraefschèpe, F. Dubas, and D. Lhotellier, "Modeling of a coaxial magnetic gear equipped with surface mounted PMs using nonlinear adaptive magnetic equivalent circuits," in Proc. ICEM, Lausanne, Switzerland, Sep. 04-07, 2016.

[23] Sh. Utegenova, F. Dubas, M. Janot, R. Glises, B. Truffart, D. Mariotto, P. Lagonotte, and Ph. Desevaux, "An investigation into the coupling of magnetic and thermal analysis for wound-rotor synchronous machine," IEEE Trans. on Ind. Elec., 2017, DOI: 10.1109/TIE.2017.2756597.

[24] Flux2D/3D, "General operating instructions", Version 11.1., Cedrat S.A. Electrical Engineering, Grenoble, France, 2013.

[25] A. Marrocco, "Analyse numérique de problèmes d'électrotechnique", Ann. Sc. Math., vol. 01, pp. 271-296, 1977

[26] F. Dubas, and A. Rahideh, "2-D analytical PM eddy-current loss calculations in slotless PMSM equipped with surface-inset magnets,' IEEE Trans. on Magn., vol. 50, no. 3, Art. ID 6300320, Mar. 2014. 